ARTICLE

\title{
Cross-reactive serum and memory B-cell responses to spike protein in SARS-CoV-2 and endemic coronavirus infection
}

Ge Song1,2,3,7, Wan-ting He 1,2,3,7, Sean Callaghan1,2,3, Fabio Anzanello1,2,3, Deli Huang (D) 1, James Ricketts (1) 1, Jonathan L. Torres (1) 4, Nathan Beutler (1) 1, Linghang Peng1', Sirena Vargas 1,2,3, Jon Cassell1,2,3, Mara Parren', Linlin Yang ${ }^{1}$, Caroline Ignacio ${ }^{5}$, Davey M. Smith ${ }^{5}$, James E. Voss (D) ${ }^{1}$, David Nemazee (iD ${ }^{1}$, Andrew B. Ward (D) 2,3,4, Thomas Rogers ${ }^{1,5}$, Dennis R. Burton (i) ${ }^{1,2,3,6 凶}$ \& Raiees Andrabi (iD 1,2,3凶

Pre-existing immunity to seasonal endemic coronaviruses could have profound consequences for antibody responses to SARS-CoV-2, induced from natural infection or vaccination. A first step to establish whether pre-existing responses can impact SARS-CoV-2 infection is to understand the nature and extent of cross-reactivity in humans to coronaviruses. Here we compare serum antibody and memory $B$ cell responses to coronavirus spike proteins from pre-pandemic and SARS-CoV-2 convalescent donors using binding and functional assays. We show weak evidence of pre-existing SARS-CoV-2 cross-reactive serum antibodies in prepandemic donors. However, we find evidence of pre-existing cross-reactive memory $B$ cells that are activated during SARS-CoV-2 infection. Monoclonal antibodies show varying degrees of cross-reactivity with betacoronaviruses, including SARS-CoV-1 and endemic coronaviruses. We identify one cross-reactive neutralizing antibody specific to the S2 subunit of the $S$ protein. Our results suggest that pre-existing immunity to endemic coronaviruses should be considered in evaluating antibody responses to SARS-CoV-2.

\footnotetext{
${ }^{1}$ Department of Immunology and Microbiology, The Scripps Research Institute, La Jolla, CA, USA. ${ }^{2}$ IAVI Neutralizing Antibody Center, The Scripps Research Institute, La Jolla, CA, USA. ${ }^{3}$ Consortium for HIV/AIDS Vaccine Development (CHAVD), The Scripps Research Institute, La Jolla, CA, USA. ${ }^{4}$ Department of Integrative Structural and Computational Biology, The Scripps Research Institute, La Jolla, CA, USA. ${ }^{5}$ Division of Infectious Diseases, Department of Medicine, University of California, San Diego, La Jolla, CA, USA. ${ }^{6}$ Ragon Institute of Massachusetts General Hospital, Massachusetts Institute of Technology,

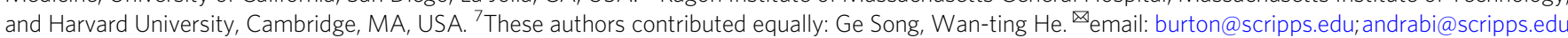


W ell-known examples of pre-existing immunity to viruses influencing antibody $(\mathrm{Ab})$ responses to related viruses include original antigenic sin (OAS) in influenza virus infections and $\mathrm{Ab}$-dependent enhancement (ADE) in flavivirus infections ${ }^{1-3}$. There is considerable interest in establishing whether $\mathrm{Ab}$ or $\mathrm{T}$-cell responses to SARS-CoV-2, through infection or vaccination, might be impacted by pre-existing immunity to other coronaviruses, particularly the endemic coronaviruses (endemic $\mathrm{HCoVs}$ ), namely the betacoronaviruses ( $\beta$ $\mathrm{HCoV}), \mathrm{HCoV}-\mathrm{HKU} 1$ and $\mathrm{HCoV}-\mathrm{OC} 43$, and the alphacoronaviruses ( $\alpha-\mathrm{HCoV}), \mathrm{HCoV}-\mathrm{NL} 63$ and $\mathrm{HCoV}-229 \mathrm{E}$, which are responsible for non-severe infections such as common colds ${ }^{4-8}$. In principle, pre-existing immune perturbation effects could occur by the interaction of SARS-CoV-2 with cross-reactive circulating serum Abs or with B cells bearing cross-reactive B-cell receptors (BCRs) or $\mathrm{T}$ cells with cross-reactive $\mathrm{T}$-cell receptors. Although a number of studies have reported on cross-reactive $\mathrm{T}$ cells and serum $\mathrm{Abs}^{5,7,9-12}$, we investigate here both $\mathrm{Ab}$ and BCR cross-reactivities.

\section{Results}

Since individuals who have been infected with SARS-CoV-2 will generally also have been infected with endemic $\mathrm{HCoVs}$, we chose to compare COVID-19 and pre-pandemic donors in terms of serum Abs and BCRs with specificity for the spike (S) protein (Supplementary Table 1 summarizes the demographic details of the human cohorts). The rationale was that the pre-pandemic donor cross-reactive responses in COVID-19 donors could have originated from endemic $\mathrm{HCoV}$ infection. Additinally, the COVID-19 cohort could reveal the effects of SARS-CoV-2 infection on cross-reactive responses.

To assess serum Ab S-protein binding in the two cohorts, we used cell surface bound and recombinant soluble S-proteins. We employed both binding assays in parallel to assess any potential differences in the serum Ab-binding patterns that may result from the engineering and truncation of the soluble $\mathrm{HCoV} S$ protein relative to the membrane-bound protein. HIV envelope studies have revealed that the cell surface-expressed envelope trimers may more closely mimic infectious virion-associated envelope spikes, including in terms of native-like glycan compositions $^{13,14}$. First, we developed and utilized a highthroughput flow cytometry-based cell surface spike-binding assay (cell-based enzyme-linked immunosorbent assay; CELISA). COVID-19 convalescent sera from 36 donors showed strong reactivity to the SARS-CoV-2 spike in the vast majority of infected donors (Fig. 1a, Supplementary Fig. 1), somewhat lower reactivity with the SARS-CoV-1 spike and much lower reactivity with the MERS-CoV spike in a pattern consistent with sequence conservation between the three viruses. COVID sera also exhibited strong cross-reactivity with endemic $\mathrm{HCoV}$ spikes, especially with the HCoV-HKU1 and HCoV-OC43 $\beta$-HCoVs (Fig. 1a). The $\alpha-\mathrm{HCoV}$-derived HCoV-NL63 spike was least reactive among the four endemic HCoVs. Next, we tested sera from a cohort of 36 HIV seropositive but otherwise healthy human donors whose samples were collected pre-pandemic. The sera showed minimal or no reactivity to SARS-CoV-2/CoV-1 and MERS-CoV spikes but showed strong binding to the endemic $\mathrm{HCoV}$ spikes, especially against the HCoV-HKU1 and HCoV-OC43 $\beta$-HCoVs (Fig. 1, Supplementary Fig. 1). The results suggest that the prepandemic sera, at least in our cohort, possess low levels of preexisting SARS-CoV-2-circulating Abs.

To further investigate, we generated recombinant soluble Sproteins of all seven HCoVs using a general stabilization strategy described elsewhere ${ }^{15-17}$. ELISA showed a similar binding pattern of the COVID and pre-pandemic sera as the CELISA (Fig. 1b,
Supplementary Fig. 1). The SARS-CoV-2 S-specific binding of COVID sera in the two assay formats (CELISA versus ELISA) correlated strongly $(r=0.92, p<0.001)$ (Supplementary Fig. 2), the titers detected in ELISA being substantially lower overall. Differential sensitivity of the two assay formats may reflect an inherently greater sensitivity of flow cytometry (CELISA) compared with ELISA but also to the potential effects of engineering on the soluble $\mathrm{HCoV} \mathrm{S}$-proteins that may reduce nativity of some epitopes. We also tested the neutralization of the COVID sera with SARS-CoV-2 and the $\mathrm{ID}_{50}$ neutralization titers positively correlated with both binding assays (CELISA $(r=0.72, p<$ $0.0001)$, ELISA $(r=0.68, p<0.0001)$ ) (Supplementary Fig. 2). Overall, both CELISA and ELISA revealed binding Abs to all seven $\mathrm{HCoV}$ spikes in COVID sera but only to endemic HCoVs in the pre-pandemic sera.

To assess whether SARS-CoV-2 infection may impact serum $\mathrm{Ab}$ titers to endemic $\mathrm{HCoVs}$, we compared $\mathrm{Ab}$ titers to endemic $\mathrm{HCoV}$ S-protein in sera from COVID and pre-pandemic cohorts. Higher CELISA Ab titers to endemic HCoV-HKU1 S-protein, but not for other $\mathrm{HCoV}$ spikes (HCoV-OC43, HCoV-NL63, and HCoV-229E) were observed in the COVID cohort compared with the pre-pandemic cohort (Supplementary Fig. 3). The result suggests that SARS-CoV-2 infection may boost titers to the related HCoV-HKU1 spike ${ }^{18,19}$. To further investigate, we divided individuals from the COVID cohort into two groups, one with the higher SARS-CoV-2 spike Ab titers (area-under-the-curve (AUC) $>85,000$ ) and the other with lower titers (AUC $<85,000)$. Consistent with the above result, the COVID sera with higher SARS$\mathrm{CoV}-2$ titers showed significantly higher binding to $\mathrm{HCoV}-\mathrm{HKU} 1$ and $\mathrm{HCoV}$-OC43 S-proteins compared with the low titer group (Supplementary Fig. 3). The a-HCoVs HCoV-NL63 and HCoV229E spike-binding Ab titers were comparable between the two groups and served as a control (Supplementary Fig. 3). As the two cohorts are not matched in terms of a number of parameters and are of limited size, any conclusions should be treated with caution. Nevertheless, it is noteworthy that SARS-CoV-2 infection is apparently associated with enhanced $\beta$-HCoVs S-protein $A b$ responses. A key question is whether the enhanced responses arise from de novo B-cell responses or from a recall response of B cells originally activated by an endemic $\mathrm{HCoV}$ virus infection.

We were encouraged to look more closely at the Abs involved by BioLayer Interferometry (BLI). Polyclonal serum antibodies were used as analytes with biotinylated S-proteins captured on streptavidin biosensors. As the concentrations of the $S$ protein-specific polyclonal Abs in the sera are unknown, these measurements can provide an estimate of $\mathrm{Ab}$ dissociation off-rates ( $k_{\mathrm{off}}$, which is $\mathrm{Ab}$ concentration-independent) but not binding constants ${ }^{20}$. Slower dissociation off-rates would indicate greater affinity maturation of antibodies with a given $S$ protein ${ }^{21}$. It is important to note that the off-rates are likely associated with bivalent IgG binding (avidity) in the format used. Consistent with the notion of SARS-CoV-2 infection activating a recall of cross-reactive $\mathrm{HCoV}$ S-specific Abs, the COVID sera Abs exhibited significantly slower off-rates with $\mathrm{HCoV}-\mathrm{HKU} 1$ and HCoV-NL63 S-proteins compared with prepandemic sera Abs (Fig. 2a-b, Supplementary Fig. 4).

Our hypothesis is that the increased affinity of cross-reactive Abs to endemic HCoVs in COVID donors arises from B-cell recall by SARS-CoV-2 heterologous boost. There is evidence from other studies that heterologous boosting can strongly drive $\mathrm{B}$ cell affinity maturation. For example, HIV infection has been shown to drive unusually high affinity maturation ${ }^{21-26}$. Presumably, the repeated exposure of B cells to a constantly diversifying epitope trains B cells to affinity mature with more diverse features within an epitope and increased somatic hypermutation (SHM). This idea is also supported by vaccination studies involving HIV antigens in engineered mice ${ }^{27,28}$. Another example 

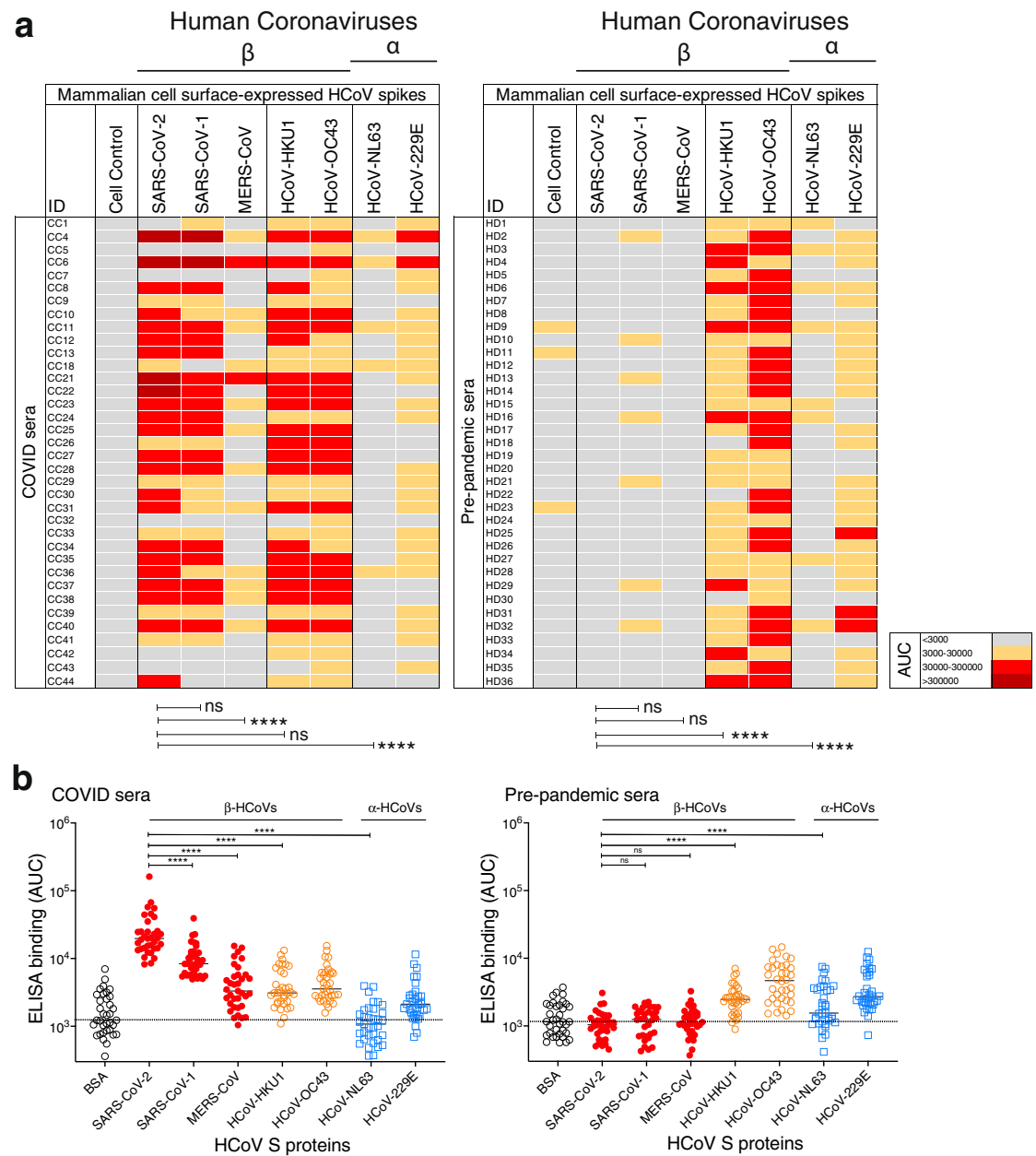

Fig. 1 Reactivity of COVID and pre-pandemic human sera with cell surface-expressed human coronaviruses spikes and their soluble S-protein versions. a Heatmap showing cell-based flow cytometry binding (CELISA) of COVID and pre-pandemic donor sera with 293 T-cell surface-expressed fulllength spike proteins from $\beta$-(SARS-CoV-2, SARS-CoV-1, MERS-CoV, HCoV-HKU1, HCoV-OC43) and $\alpha$-(HCoV-NL63 and HCoV-229E) human coronaviruses ( $\mathrm{HCoVs}$ ). Sera were titrated (six dilutions-starting at 1:30 dilution) and the extent of binding to cell surface-expressed HCoVs was recorded by $\%$ positive cells, as detected by PE-conjugated anti-human-Fc secondary Ab using flow cytometry. Area-under-the-curve (AUC) was calculated for each binding titration curve and the antibody titer levels are color-coded as indicated in the key. The binding of sera to vector-only plasmid (non-spike) transfected 293 T cells served as a control for non-specific binding. b ELISA binding of COVID and pre-pandemic donor sera to soluble S-proteins from $\beta$ (SARS-CoV-2, SARS-CoV-1, MERS-CoV, HCoV-HKU1, HCoV-OC43) and $\alpha$-(HCoV-NL63 and HCoV-229E) HCoVs. Serum dilutions (eight

dilutions-starting at 1:30 dilution) were titrated against the S-proteins and the binding was detected as OD405 absorbance. AUC representing the extent of binding was calculated from binding curves of COVID (left) and pre-pandemic (right) sera with S-proteins and comparisons of antibody binding titers are shown. The binding of sera with each protein is shown as scatter dot plots with a line at median. Binding to BSA served as a control for non-specific binding by the sera. The serum-binding experiments were carried out in duplicate and repeated independently at least once for reproducibility. Statistical comparisons between two groups were performed using a Mann-Whitney two-tailed test, $\left({ }^{\star \star \star} p<0.0001 ; n s p>0.05\right)$.

is for human infections with two distinct flaviviruses. We previously showed that Zika virus infection in humans resulted in a strong recall of dengue-specific cross-reactive $\mathrm{Ab}$ responses from pre-existing dengue-specific memory $\mathrm{B}$ cells ${ }^{29}$. The cross-reactive recall B-cell responses had more mutations and higher apparent affinity for antigens from the earlier infection (dengue virus in this case) than against the antigens from the latter infection (Zika virus in this case).

Having probed serum cross-reactivity between coronaviruses, we next investigated memory B cells in COVID individuals. We examined the reactivities of IgG + memory B cells in eight select COVID donors (based on differential binding to $\mathrm{HCoV}$ spikes (Fig. 1) with SARS-CoV-2, HCoV-HKU1 ( $\beta-\mathrm{HCoV})$, and HCoVNL63 ( $\alpha$-HCoV) S-proteins by flow cytometry. Up to $~ 8 \%$ SARSCoV-2 S-protein, $4.3 \% \mathrm{HCoV}$-HKU1 S-protein and $\sim 0.6 \%$ for HCoV-NL63 S-protein-specific B cells were identified (Fig. 3a-b,
Supplementary Fig. 5) in a frequency pattern consistent with serum Ab-binding titers.

To probe the specificities of SARS-CoV-2/endemic $\mathrm{HCoV}$ cross-reactive Abs, we sorted single B cells for either SARS-CoV2/HCoV-HKU-1 or SARS-CoV-2/HCoV-NL63 CoV S-protein double positivity. We isolated $20 \mathrm{~S}$-protein-specific mAbs from four COVID donors, CC9 $(n=3), \operatorname{CC10}(n=3), \operatorname{CC} 36(n=6)$, and CC40 $(n=8)$ (Fig. 3c, Supplementary Fig. 6) but only five mAbs, three from the CC9 donor and two from the CC40 donor, exhibited cross-reactive binding with HCoV-HKU1 spike (Fig. 3e). Two of the cross-reactive mAbs from the CC9 donor (CC9.1 and CC9.2) were clonally related. All five of the SARSCoV-2/ HCoV-HKU-1 cross-reactive mAbs displayed binding to the genetically related $\beta-\mathrm{HCoV}, \mathrm{HCoV}-\mathrm{OC} 43$, spike but not to the $\alpha$-HCoVs, HCoV-NL63, and HCoV-229E, spikes (Fig. 4a, Supplementary Fig. 7). Notably, one mAb (CC9.3) exhibited 


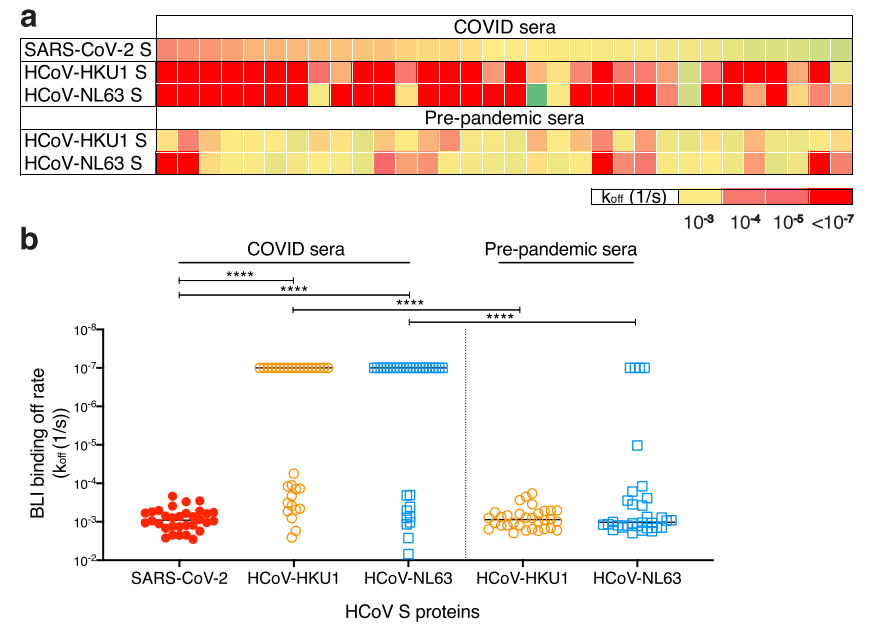

Fig. 2 BioLayer interferometry binding of COVID and pre-pandemic serum antibodies to SARS-CoV-2 and endemic HCoV S-proteins. a

Heatmap summarizing the apparent BLI binding off-rates $\left(k_{\text {off }}(1 / s)\right)$ of the COVID and pre-pandemic human serum antibodies to SARS-CoV-2 $S$ and endemic $\beta$-HCoV, HCoV-HKU1 and $\alpha-\mathrm{HCoV}, \mathrm{HCoV}-\mathrm{NL} 63$ S-proteins. Biotinylated HCoV S-proteins (100 nM) were captured on streptavidin biosensors to achieve binding of at least one response unit. The S-proteinimmobilized biosensors were immersed in 1:40 serum dilution solution with serum antibodies as the analyte and the association (120 s; 180-300) and dissociation (240 s; 300-540) steps were conducted to detect the kinetics of antibody-protein interaction. $k_{\text {off }}(1 / s)$ dissociation rates for each antibody-antigen interaction are shown. $\mathbf{b}$ Off-rates for binding of serum antibodies from COVID donors and from pre-pandemic donors to SARSCoV-2 S and endemic HCoV, HCoV-HKU1, and HCoV-NL63, S-proteins. Significantly lower dissociation off-rates are observed for COVID compared with pre-pandemic sera. Statistical comparisons between the two groups were performed using a Mann-Whitney two-tailed test, $\left({ }^{\star \star \star *} p<0.0001\right)$.

binding to five out of the seven HCoVs, including the MERS-CoV S-protein (Fig. 4a, Supplementary Fig. 7), suggesting targeting of a highly conserved epitope on $\beta-\mathrm{HCoV}$ spikes. One of the four SARS-CoV-2/HKU1-CoV S cross-reactive mAbs (CC40.8) showed weak cross-neutralization against SARS-CoV-2 and SARS-CoV-1 viruses (Supplementary Fig. 7). Except for CC9.3 $\mathrm{mAb}$, all cross-reactive mAbs were encoded by $\mathrm{VH} 3$ heavy chain gene family (Supplementary Figs. 6 and 7) and possessed $5.6-10.4 \%($ median $=6.6 \%)$ VH and $3.1-4.4 \%($ median $=3.9 \%)$ VL nucleotide SHMs (Fig. 3d Supplementary Fig. 6).

In principle, the SARS-CoV-2/HCOV-HKU1 S cross-reactive memory B cells could be pre-existing in the COVID donors and show cross-reactivity with SARS-CoV-2 or originate from the SARS-CoV-2 infection and show cross-reactivity with $\mathrm{HCoV}$ HKU1 S protein. The levels of SHM in the five cross-reactive mAbs listed above argue for the former explanation. To gain further insight, we conducted BLI-binding studies on the three cross-reactive mAbs, CC9.2, CC9.3, and CC40.8 (Fig. 4b). Both bivalent IgGs and monovalent Fabs showed enhanced binding affinity to $\mathrm{HCoV}$-HKU1 S-protein compared with SARS-CoV-2 S-protein (Fig. 4b) again consistent with the notion that the Abs (BCRs) arise from a pre-existing $\mathrm{HCoV}-\mathrm{HKU} 1 \mathrm{~S}$ response. The serum and BCR data are then consistent. The data above suggests elevated serum levels of Abs to $\mathrm{HCoV}-\mathrm{HKU1} \mathrm{S}$-protein in COVID donors compared with pre-pandemic donors (Fig. 2a-b) is consistent with the notion that SARS-CoV-2 activates $B$ cells expressing pre-existing HCoV-HKU1 S-protein-specific BCRs to secrete the corresponding Abs.

In general, it should be noted that although our study provides evidence for a recall of cross-reactive Abs upon SARS-CoV-2 infection, the most definitive demonstration of the origins of cross-reactive $\mathrm{Ab}$ responses would come from longitudinal human studies of donors before and after SARS-CoV-2 infection.

One mechanism by which pre-existing cross-reactive antibodies might influence the course of SARS-CoV-2 infection is ADE. Therefore, we investigated the potential ADE of the three cross-reactive Abs using a SARS-CoV-2 live virus assay (Fig. 4c). Of the three cross-reactive antibodies, CC9.3 mAb showed a marginal increase (twofold) in infection of SARS-CoV-2 virus in the Fc $\gamma$ RIIa (K562) and Fc $\gamma$ RIIb (Daudi) expressing target cells that can mediate ADE. Further in vivo assessment would be needed to determine whether this activity is associated with any meaningful physiological effects.

To map the epitope specificities of the cross-reactive mAbs, we evaluated binding to a number of fragments of the S-protein (Fig. 5a-b). Notably, all five of the SARS-CoV-2/HKU1-CoV cross-reactive $\mathrm{mAbs}$ failed to bind any of the $\mathrm{S} 1$ subunit domains or subdomains, suggesting targeting to the more conserved S2 subunit. To identify the cross-reactive neutralizing epitope recognized by $\mathrm{mAb} C \mathrm{C} 40.8$, we conducted structural studies of the $\mathrm{Ab}$ with the HKU1-CoV S protein. Using single-particle negative stain electron microscopy (nsEM) we observed that CC40.8 bound to the HCoV-HKU1 S trimer near the bottom of the S2 domain (Fig. $5 c-d$ ). The Fab density in the 2D class averages was blurry, suggesting binding to a flexible surface exposed peptide. The flexibility also precluded further 3D reconstruction.

Despite the requirement of double positivity in the B-cell sorting, 15/20 mAbs were largely specific for SARS-CoV-2. Again, like cross-reactive mAbs above, the vast majority of SARS-CoV2-specific mAbs were encoded by VH3 gene family (Fig. 3c, Supplementary Fig. 6), consistent with other studies ${ }^{30-37}$. Overall, the SARS-CoV-2 spike antigenic surface can be recognized by various human $\mathrm{VH}$-gene families, but there is a bias toward the VH3 gene-encoded antibodies and rational vaccine design strategies may take this feature into consideration. VH-germline gene-specific bias for antigenic shapes is common and has been previously reported for many pathogen surfaces ${ }^{38-40}$. Compared with the cross-reactive mAbs, the nucleotide SHM levels in SARSCoV-2-specific mAbs were much lower $(\mathrm{VH}, 0-11.6 \%$ (median $=0.7 \%) \mathrm{VL}, 0-4.2 \%($ median $=1.3 \%)$ ) (Fig. 3d Supplementary Fig. 6). Three of the 15 SARS-CoV-2 S-specific mAbs showed neutralization against SARS-CoV-2 virus, CC40.1 being the most potent (Fig. 3f, Supplementary Fig. 7). Some of the SARS-CoV-2specific mAbs exhibited cross-reactive binding with SARS-CoV-1 $\mathrm{S}$ protein but none neutralized SARS-CoV-1 virus.

\section{Discussion}

In conclusion, using a range of immune monitoring assays, we compared the serum and memory B-cell responses to the Sprotein from all seven coronaviruses infecting humans in SARS$\mathrm{CoV}-2$ donors and in pre-pandemic donors. In sera from our prepandemic cohort, we found no evidence of pre-existing SARSCoV-2 S-protein reactive antibodies that resulted from endemic $\mathrm{HCoV}$ infections, consistent with other studies ${ }^{41,42}$. A recent study has, however, reported the presence of SARS-CoV-2 Sprotein reactive antibodies in a small fraction of pre-pandemic human sera from children and adolescents ${ }^{11}$. An in-depth examination for the presence of SARS-CoV-2 S-protein reactive antibodies in large pre-pandemic human cohorts is warranted to reliably determine the frequency of such antibodies. Notably, we observed serum levels of endemic $\mathrm{HCoV}$ S-protein antibodies were higher in SARS-CoV-2-experienced donors and memory Bcell studies suggested these likely arose from SARS-CoV-2 infection activating cross-reactive endemic $\mathrm{HCoV}$ S-protein- 
a

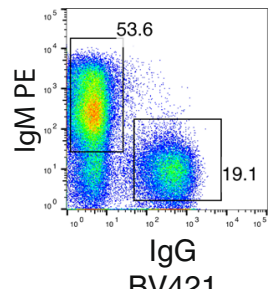

BV421
CC9 sample gated on IgG+B cells
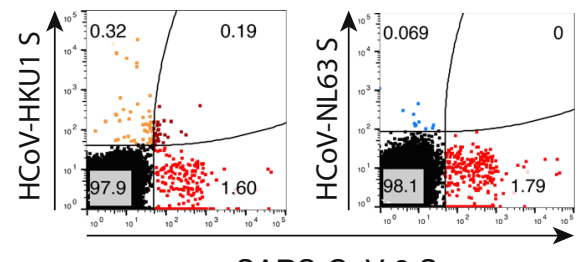

SARS-CoV-2 S

b HCoV S specificity

- SARS-CoV-2 S SARS-CoV-2 S + HCOV-HKU1 S

- HCoV-HKU1S SARS-CoV-2 S + HCoV-NL63S

- HCoV-NL63S

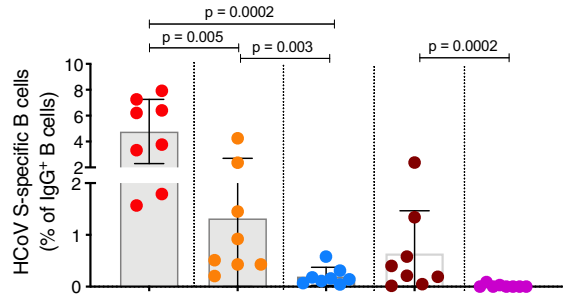

C

Cc9
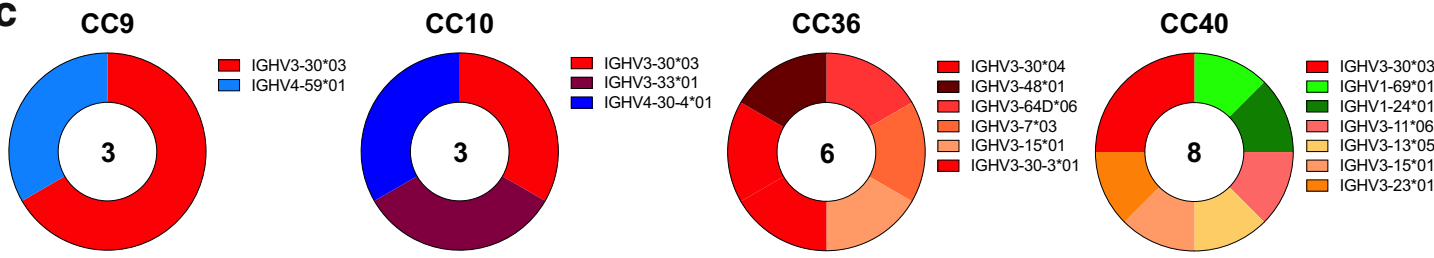

d

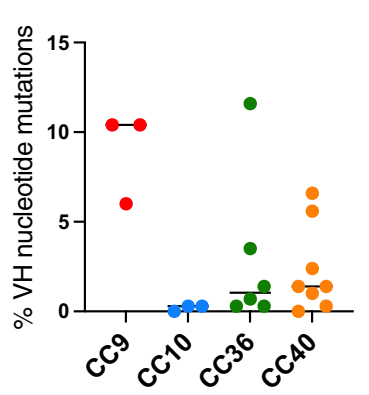

e

\section{SARS-CoV-2 spike}
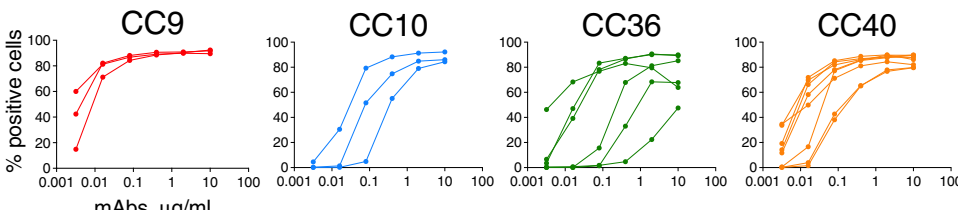

$\mathrm{mAbs}, \mu \mathrm{g} / \mathrm{ml}$

HCoV-HKU1 spike
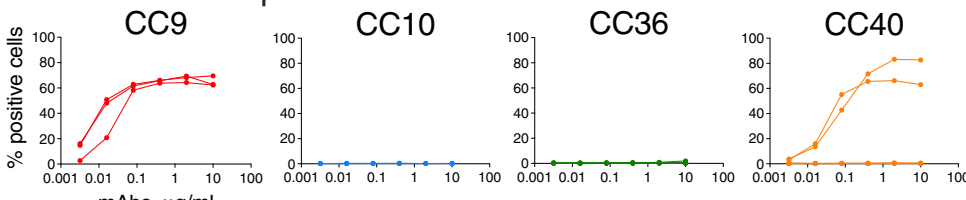

f

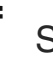

SARS-CoV-2 virus
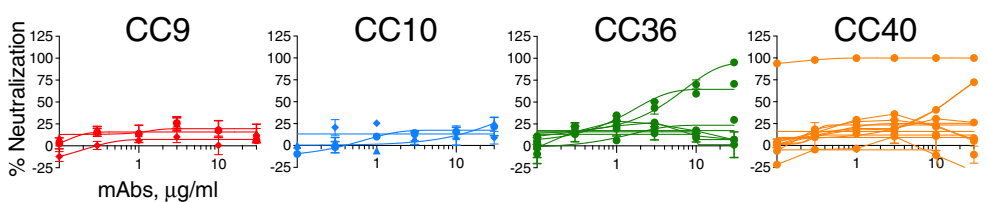

mAbs, $\mu \mathrm{g} / \mathrm{m}$

Fig. 3 SARS-CoV-2 S and endemic HCoV S-protein-specific cross-reactive IgG + memory B cells from COVID donors and isolation and characterization of $\mathbf{m A b s}$. a-b. Flow cytometry analysis showing the single B-cell sorting strategy for COVID representative donor CC9 and frequencies of SARS-CoV-2 S and endemic $\beta-\mathrm{HCoV}, \mathrm{HCoV}-\mathrm{HKU1}$ and $\alpha-\mathrm{HCoV}, \mathrm{HCoV}-\mathrm{NL} 63 \mathrm{~S}$-protein-specific memory B cells in eight select COVID donors. The B cells were gated as SSL, CD3-, CD4-, CD8-, CD14-, IgD-CD19+, IgM-, IgG+. The frequencies of HCoV S-protein-specific IgG memory B cells were as follows; SARSCoV-2 S (up to $\sim 8 \%$-range $=\sim 1.6-8 \%$ ), HCoV-HKU1 S (up to $\sim 4.3 \%$-range $=\sim 0.2-4.3 \%$ ), HCoV-NL63 S (up to $\sim 0.6 \%-$ range $=\sim 0.04-0.6 \%$ ) protein single positive and SARS-CoV-2/HCoV-HKU1 S (up to $\sim 2.4 \%$-range $=\sim 0.02-2.4 \%$ ) and SARS-CoV-2/HCoV-NL63 S-protein (up to $\sim 0.09 \%-$ range $=$ $\sim 0-0.09 \%$ ) double positives. SARS-CoV-2-infected donors showed the presence of SARS-CoV-2/HCoV-HKU1 S-protein cross-reactive IgG memory B cells. Scatter dot plots show frequencies of S protein-specific B cells with a line at mean with SD. All differences between means with $p$ values for each comparison are indicated. ${ }^{\star \star} p<0.01 ;{ }^{\star \star \star} p<0.001$. A Mann-Whitney two-tailed test was used to compare the data groups. c Pie plots showing immunoglobulin heavy chain distribution of mAbs isolated from four COVID donors, CC9, CC10, CC36, and CC40. The majority of the mAbs were encoded by the IgVH3 immunoglobulin gene family. $\mathbf{d}$ Plots showing \% nucleotide mutations in heavy (VH) and light (VL) chains of isolated mAbs across different individuals. The VH and VL mutations ranged from 0 to $11.6 \%$ and $0-4.4 \%$, respectively, and are shown as scatter dot plots with a line at median. e CELISA-binding curves of isolated mAbs from four COVID donors with SARS-CoV-2 and HCoV-HKU1 spikes expressed on $293 \mathrm{~T}$ cells. Binding to HCoV spikes is recorded as \% positive cells using a flow cytometry method. Five mAbs, three from the CC9 donor, and two from the CC40 donor show crossreactive binding to SARS-CoV-2 and HCoV-HKU1 spikes. $\mathbf{f}$ Neutralization of SARS-CoV-2 by mAbs isolated from COVID donors. Four mAbs, two each from donors, CC36 and CC40, show neutralization of SARS-CoV-2. The neutralization experiments were performed in duplicate and repeated independently 1-2 times for reproducibility.

specific B cells. Cross-reactive mAbs largely target the more conserved S2 subunit on S-proteins and we identified a SARSCoV-2 cross-neutralizing epitope that could facilitate vaccine design and Ab-based intervention strategies. Indeed, studies have shown targeting of conserved S2 subunit-neutralizing epitopes in SARS-CoV-2-infected donors and by SARS-CoV-1 nAbs that may potentially display activities against a broader range of human coronaviruses ${ }^{43-46}$. Overall, our study highlights the need 


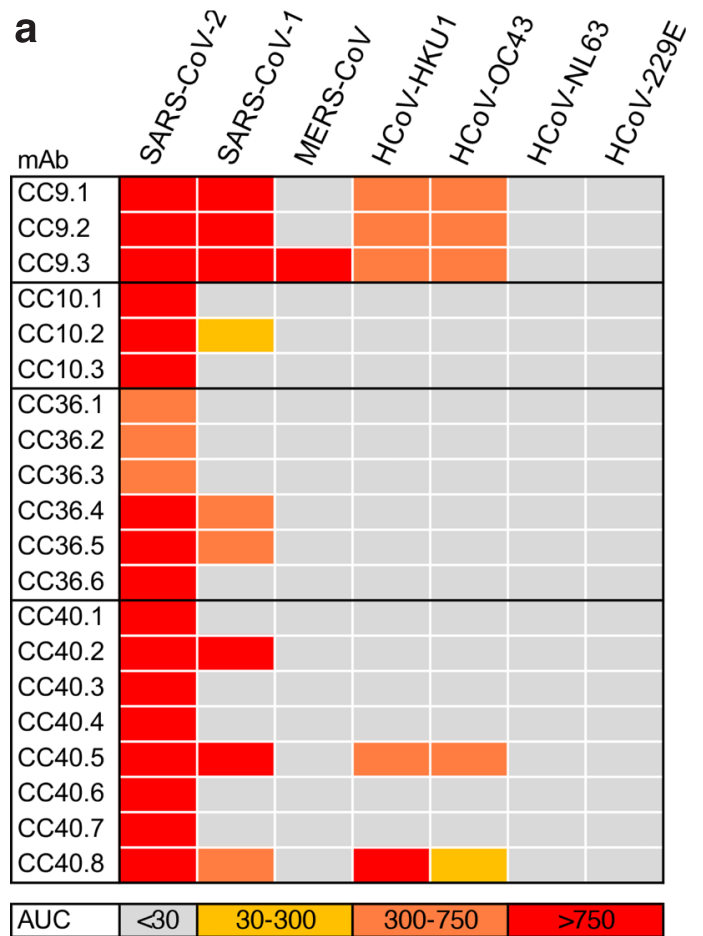

\section{b SARS-CoV-2 S}
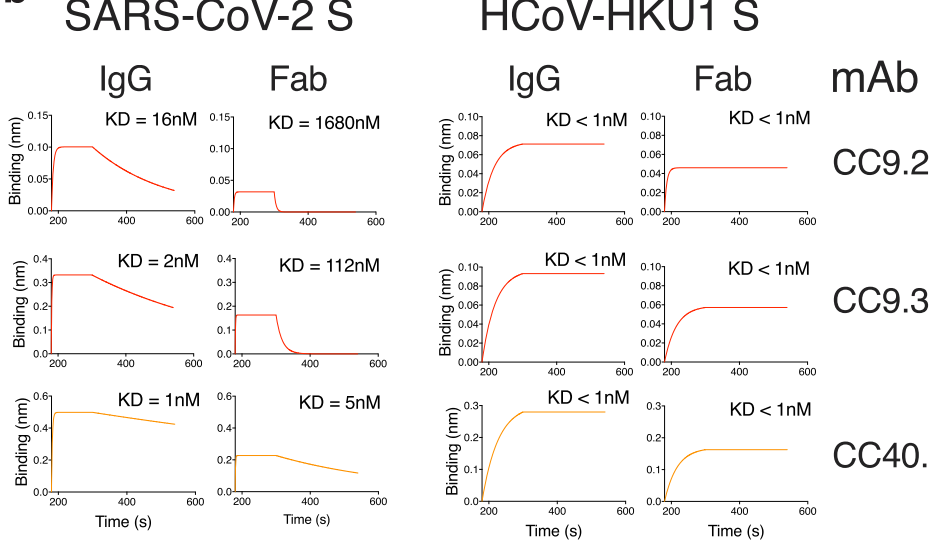

CC9.3
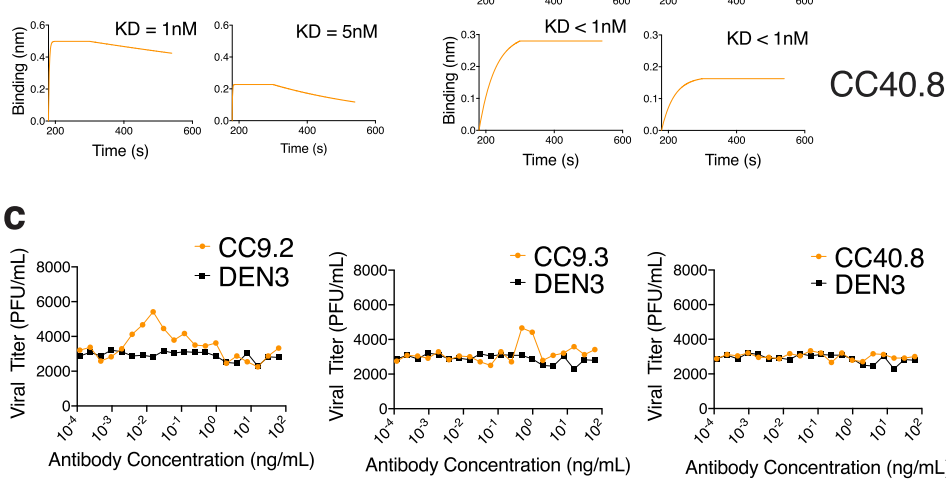

Fig. 4 Binding and ADE of SARS-CoV-2/HCoV-HKU1 S-protein-specific cross-reactive mAbs. a Heatmap showing CELISA binding of COVID mAbs to seven $\mathrm{HCoV}$ spikes. Binding represented as area-under-the-curve (AUC) is derived from CELISA-binding titrations of mAbs with cell surface-expressed $\mathrm{HCoV}$ spikes and the extent of binding is color-coded. Five mAbs show cross-reactive binding across $\beta-\mathrm{HCoV}$ spikes. $\mathbf{b}$ BLI of SARS-CoV-2 and HCoVHKU1 S-protein-specific cross-reactive mAbs. BLI binding of both IgG and Fab versions of three cross-reactive mAbs (CC9.2, CC9.3, and CC40.8) to SARSCoV-2 and HCoV-HKU1 S-proteins was tested and the binding curves show association (120 s; 180-300) and dissociation rates (240 s; $300-540$ ). BLI binding of antibody-S-protein combinations shows more stable binding (higher binding constants (KDs)) of cross-reactive mAbs HCoV-HKU1 compared to the SARS-CoV-2 S protein. c Antibody-dependent enhancement (ADE) activities of cross-reactive mAbs, CC9.2, CC9.3, and CC40.8 binding to SARSCoV-2 live virus using FcyRlla (K562) and FcyRllb (Daudi)-expressing target cells. A dengue antibody, DEN3, was used as a control. Each data point in the curve is derived from the ADE experiment of mAbs with SARS-CoV-2 virus and shows virus titer obtained from technical replicates ( $n=2$ ); data representative of two independent experiments.

to understand fully the nature of pre-existing endemic $\mathrm{HCoV}$ immunity in large and diverse human cohorts as vaccination of hundreds of millions of people against COVID-19 goes forward.

\footnotetext{
Methods

Human cohort information. Plasma and PBMCs from convalescent COVID patients were kindly provided through the "Collection of Biospecimens from Persons Under Investigation for 2019-Novel Coronavirus Infection to Understand Viral Shedding and Immune Response Study" UCSD IRB\# 200236. Plasma from pre-pandemic donors was provided by Primary Infection Resource Consortium UCSD IRB\# 140093 and 191008. These donors were from an HIV-1-positive healthy cohort of individuals with well-controlled HIV-1 and were on ARV. These pre-pandemic samples were collected from 18 April 2019 to 3 March 2020 before the spread of the pandemic in the United States. The protocol was approved by the UCSD Human Research Protection Program. COVID patient samples were collected based on COVID-19 diagnosis regardless of gender, race, ethnicity, disease severity, or other medical conditions. The age and the ethnicity variables were relatively evenly distributed across the two human cohorts (COVID and prepandemic samples). The gender distribution in the pre-pandemic cohort could not be controlled owing to the unavailability of the samples from female donors. The gender for individuals in the COVID cohort was evenly distributed. All human donors were assessed for medical decision-making capacity using a standardized, approved assessment, and voluntarily gave informed consent prior to being enrolled in the study. The summary of the demographic information of the COVID patients and pre-pandemic donors is listed in Supplementary Table 1.
}

Plasmid construction for full-length and recombinant soluble proteins. To generate full-length human coronavirus plasmids, the spike genes were synthesized by GeneArt (Life Technologies). The SARS-CoV-1 (1255 amino acids; GenBank: AAP13567), SARS-CoV-2 (1273 amino acids; GenBank: MN908947), MERS-CoV (1353 amino acids; GenBank: APB87319.1), HCoV-HKU1 (1356 amino acids; GenBank: YP_173238.1), HCoV-OC43 (1361 amino acids; GenBank: AAX84792.1), HCoV-NL63 (1356 amino acids; GenBank: YP_003767.1) and
HCoV-229E (1173 amino acids; GenBank: NP_073551.1) were cloned into the mammalian expression vector phCMV3 (Genlantis, USA) using PstI and BamH restriction sites. To express the soluble $\mathrm{S}$ ectodomain protein SARS-CoV-1 (residue 1-1190), SARS-CoV-2 (residue 1-1208), MERS-CoV (residue 1-1291), HCoVHKU1 (residue 1-1295), HCoV-OC43 (residue 1-1300) and HCoV-NL63 (residue 1-1291), HCoV-229E (residue 1-1110), the corresponding DNA fragments were PCR amplified and constructed into vector phCMV3 using a Gibson assembly kit. To trimerize the soluble S-proteins and stabilize them in the prefusion state, we incorporated a C-terminal T4 fibritin trimerization motif in the C-terminal of each constructs and two consecutive proline substitutions in the S2 subunit ${ }^{15-17}$. To be specific, the K968/V969 in SARS-CoV-1, the K986/V987 in SARS-CoV-2, the V1060/L1061 in MERS-CoV, the A1071/L1072 in HCoV-HKU1, the A1078/L1079 in HCoV-OC43, the S1052/I1053 in HCoV-NL63 and the T871/I872 in HCoV$229 \mathrm{E}$ were replaced by proline residues. In addition, the S2 cleavage sites in each protein were replaced with a "GSAS" linker peptide. To facilitate the purification and biotin labeling of the soluble protein, the HRV-3C protease cleavage site, $6 \mathrm{X}$ HisTag, and AviTag spaced by GS-linkers were added to the C-terminus of the constructs, as needed. To express the SARS-CoV-2 N-terminal domain-NTD (residue 1-290), receptor-binding domain-RBD (residue 320-527), RBD-SD1 (residue 320-591), and RBD-SD1-2 (residue 320-681) subdomains, we amplified the DNA fragments by PCR reaction using the SARS-CoV-2 plasmid as template. All the DNA fragments were cloned into the vector phCMV3 (Genlantis, USA) in frame with the original secretion signal or the tissue plasminogen activator leader sequence. All the truncation proteins were fused to the C-terminal 6X HisTag, and AviTag spaced by GS-linkers to aid protein purification and biotinylation.

Expression and purification of the proteins. To express the soluble $\mathrm{S}$ ectodomain proteins of each human coronavirus and the truncated versions, the plasmids were transfected into FreeStyle293F cells (Thermo Fisher). For general production, 350 $\mu \mathrm{g}$ plasmids were transfected into $1 \mathrm{~L}$ FreeStyle $293 \mathrm{~F}$ cells at the density of 1 million cells $/ \mathrm{mL}$. We mixed $350 \mu$ g plasmids with $16 \mathrm{~mL}$ transfectagro ${ }^{\mathrm{rm}}$ (Corning) and 1.8 $\mathrm{mL} 40 \mathrm{~K}$ polyethylenimine (PEI) $(1 \mathrm{mg} / \mathrm{mL})$ with $16 \mathrm{~mL}$ transfectagro ${ }^{\text {Tx }}$ in separate $50 \mathrm{~mL}$ conical tubes. We filtered the plasmid mixture with $0.22 \mu \mathrm{m}$ Steriflip ${ }^{\mathrm{m}}$ Sterile Disposable Vacuum Filter Units (MilliporeSigma ${ }^{\mathrm{T}}$ ) before combining it with the 
a SARS-CoV-2 $S$ protein

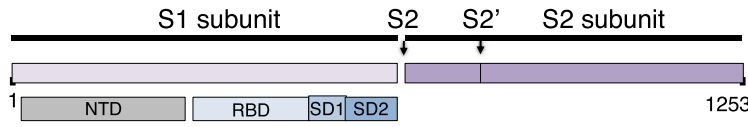

b

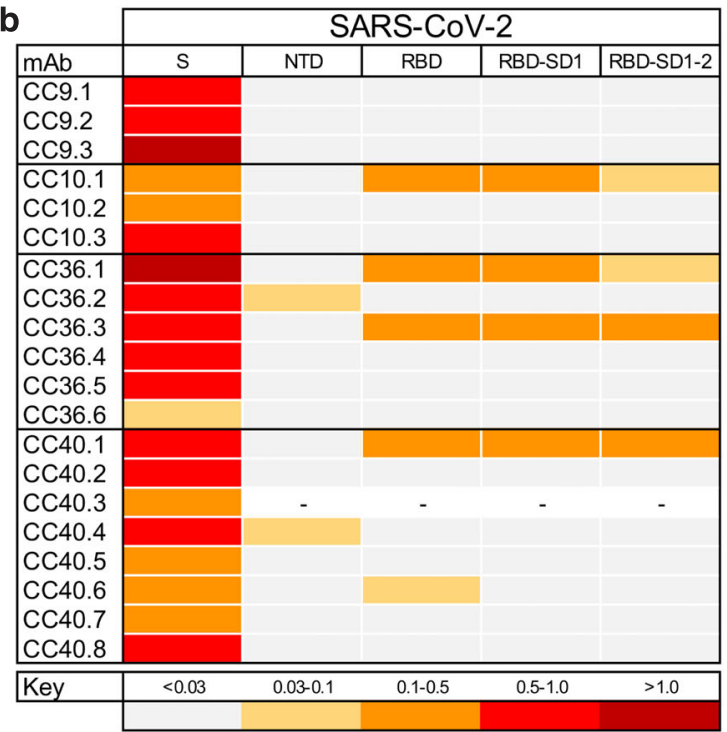

C

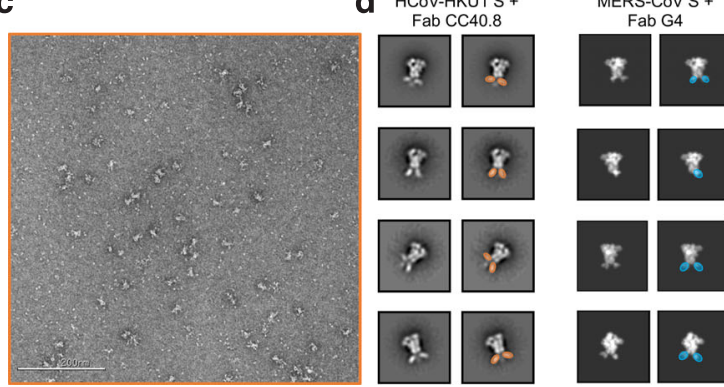

Fig. 5 Epitope specificities of SARS-CoV-2 and endemic HCoV S-protein specific cross-reactive mAbs. a-b Organization of SARS-CoV-2 S protein subunits, domains, and subdomains (a). Epitope mapping of the mAbs binding to domains and subdomains of SARS-CoV-2 S-protein, NTD, RBD, RBD-SD1, and RBD-SD1-2 and heatmap showing BLI responses for each protein. The extent of binding responses is color-coded (b). Five mAbs were specific for RBD, two for NTD and the remaining mAbs displayed binding only to the whole $\mathrm{S}$ protein. $\mathbf{c}-\mathbf{d}$ Negative stain electron microscopy of HCoV-HKU1 S-protein + Fab CC40.8 complex and comparison with MERS-CoV S + Fab G4 complex. c Raw micrograph of HCoV-HKU1 S in complex with Fab CC40.8. The Fab-HCoV-HKU1 S protein complexing was performed twice, and the data is representative of the two experiments. d Select reference-free 2D class averages with Fabs colored in orange for Fab CC40.8 and blue for Fab G4, which in 2D appear to bind a proximal epitope at the base of the trimer. 2D projections for MERS-CoV S-protein in complex with Fab G4 were generated in EMAN2 from PDB 5W9J.

PEI mixture. After gently mixing the two components, the combined solution rested at room temperature for $30 \mathrm{~min}$ and was poured into $1 \mathrm{~L}$ FreeStyle293F cell culture. To harvest the soluble proteins, the cell cultures were centrifuged at $2500 \times$ $g$ for 15 min on day 4 after transfection. The supernatants were filtered through the $0.22 \mu \mathrm{m}$ membrane and stored in a glass bottle at $4^{\circ} \mathrm{C}$ before purification. The Histagged proteins were purified with the HisPur Ni-NTA Resin (Thermo Fisher). To eliminate non-specific binding proteins, each column was washed with at least three bed volumes of wash buffer ( $25 \mathrm{mM}$ Imidazole, $\mathrm{pH}$ 7.4). To elute the purified proteins from the column, we loaded $25 \mathrm{~mL}$ of the elution buffer $(250 \mathrm{mM}$ Imidazole, $\mathrm{pH} 7.4)$ at slow gravity speed $(\sim 4 \mathrm{sec} / \mathrm{drop})$. Proteins without His tags were purified with GNL columns (Vector Labs). The bound proteins were washed with PBS and then eluted with $50 \mathrm{~mL}$ of $1 \mathrm{M}$ Methyl $\alpha$-D-mannopyranoside (Sigma M6882-500G) in PBS. By using Amicon tubes, we buffer exchanged the solution with PBS and concentrated the proteins. The proteins were further purified by size- exclusion chromatography using a Superdex 200 Increase 10/300 GL column (GE Healthcare). The selected fractions were pooled and concentrated again for further use.

Biotinylation of proteins. Random biotinylation of S-proteins was conducted using EZ-Link NHS-PEG Solid-Phase Biotinylation Kit (Thermo Scientific $\# 21440$ ). In all, $10 \mu \mathrm{l}$ dimethyl sulfoxide (DMSO) was added per tube for making concentrated biotin stock, $1 \mu \mathrm{l}$ of which were diluted into $170 \mu \mathrm{l}$ water before use. Coronavirus spike proteins were concentrated to $7-9 \mathrm{mg} / \mathrm{ml}$ using $100 \mathrm{~K}$ Amicon tubes in PBS, then aliquoted into $30 \mu \mathrm{l}$ in PCR tubes. In all, $3 \mu \mathrm{l}$ of the diluted biotin were added into each aliquot of concentrated protein and incubated on ice for $3 \mathrm{~h}$. After reaction, buffer exchange for the protein was performed using PBS to remove excess biotin. BirA biotinylation of S-proteins was conducted using BirA biotinprotein ligase bulk reaction kit (Avidity). Coronavirus S-proteins with Avi-tags were concentrated to $7-9 \mathrm{mg} / \mathrm{ml}$ using $100 \mathrm{~K}$ Amicon tubes in tris-buffered saline (TBS), then aliquoted into $50 \mu \mathrm{l}$ in PCR tubes. In all, $7.5 \mu \mathrm{l}$ of BioB Mix, $7.5 \mu \mathrm{l}$ of Biotin200, and $5 \mu \mathrm{l}$ of BirA ligase $(3 \mathrm{mg} / \mathrm{ml})$ were added per tube. The mixture was incubated on ice for $3 \mathrm{~h}$, followed by size-exclusion chromatography to segregate the biotinylated protein and the excess biotin. The extend of biotinylation was evaluated by BLI streptavidin biosensors.

CELISA binding. The binding of serum antibodies or mAbs to human coronavirus spike proteins expressed on HEK293T cell surface was determined by flow cytometry, as described previously ${ }^{47}$. HEK293T cells were transfected with plasmids encoding full-length coronavirus spikes including SARS-CoV-1, SARS-CoV-2, MERS-CoV, HCoV-HKU1, HCoV-OC43, HCoV-NL63, and HCoV-229E. Transfected cells were incubated for $36-48 \mathrm{~h}$ at $37^{\circ} \mathrm{C}$. Post incubation, cells were trypsinized to prepare a single-cell suspension and were distributed into 96-well plates Serum samples were prepared as threefold serial titrations in fluorescence-activated cell sorting (FACS) buffer ( $1 \times$ PBS, $2 \%$ fetal bovine serum (FBS), $1 \mathrm{mM}$ EDTA), starting at 1:30 dilution, six dilutions. In all, $50 \mu \mathrm{l} /$ well of the diluted samples were added into the cells and incubated on ice for $1 \mathrm{~h}$. The plates were washed twice in FACS buffer and stained with $50 \mu \mathrm{l} /$ well of 1:200 dilution of R-phycoerythrin (PE)conjugated mouse anti-human IgG Fc Ab (SouthernBiotech \#9040-09) and 1:1000 dilution of Zombie-NIR viability dye (BioLegend) on ice in dark for $45 \mathrm{~min}$. After another two washes, stained cells were analyzed using flow cytometry (BD Lyrics cytometers), and the binding data were generated by calculating the percent (\%) PE-positive cells for antigen binding using FlowJo 10 software. CR3022, a SARSCoV-1 and SARS-CoV-2 spike-binding ab, and dengue ab, DEN3, were used as positive and negative controls for the assay, respectively.

ELISA binding. In all, 96-well half-area plates (Corning cat. \#3690, Thermo Fisher Scientific) were coated overnight at $4^{\circ} \mathrm{C}$ with $2 \mu \mathrm{g} / \mathrm{ml}$ of mouse anti-His-tag $\mathrm{Ab}$ (Invitrogen cat. \#MA1-21315-1MG, Thermo Fisher Scientific) in PBS. Plates were washed three times with PBS plus 0.05\% Tween-20 (PBS-T) and blocked with 3\% (wt/vol) bovine serum albumin (BSA) in PBS for $1 \mathrm{~h}$. After removal of the blocking buffer, the plates were incubated with His-tagged spike proteins at a concentration of $5 \mu \mathrm{g} / \mathrm{ml}$ in $1 \%$ BSA plus PBS-T for $1.5 \mathrm{~h}$ at room temperature. After a washing step, perturbed and lotus serum samples were added in threefold serial dilutions in $1 \%$ BSA/PBS-T starting from 1:30 and 1:40 dilution, respectively, and incubated for $1.5 \mathrm{hr}$. CR3022 and DEN3 human antibodies were used as a positive and negative control, respectively, and added in 3-fold serial dilutions in 1\% BSA/PBS-T starting at $10 \mu \mathrm{g} / \mathrm{ml}$. After the washes, a secondary Ab conjugated with alkaline phosphatase (AffiniPure goat anti-human IgG Fc fragment specific, Jackson ImmunoResearch Laboratories cat. \#109-055-008) diluted 1:1000 in 1\% BSA/PBS-T, was added to each well. After $1 \mathrm{~h}$ of incubation, the plates were washed and developed using alkaline phosphatase substrate pNPP tablets (Sigma cat. \#S0942-200TAB) dissolved in a staining buffer. The absorbance was measured after 8,20 , and $30 \mathrm{~min}$, and was recorded at an optical density of $405 \mathrm{~nm}$ (OD405) using a VersaMax microplate reader (Molecular Devices), where data were collected using SoftMax software version 5.4. The wells without the addition of serum served as a background control.

BLI binding. An Octet K2 system (ForteBio) was used for performing the binding experiments of the coronavirus spike proteins with serum samples. All serum samples were prepared in Octet buffer (PBS plus 0.1\% Tween-20) as 1:40 dilution, random-biotinylated S-proteins were prepared at a concentration of $100 \mathrm{nM}$. The hydrated streptavidin biosensors (ForteBio) first captured the biotinylated spike proteins for $60 \mathrm{~s}$, then transferred to Octet buffer for $60 \mathrm{~s}$ to remove unbound protein and provide the baseline. Then, they were immersed in diluted serum samples for $120 \mathrm{~s}$ to provide the association signal, followed by transferring into Octet buffer to test for disassociation signal for $240 \mathrm{~s}$. The data generated were analyzed using the ForteBio Data Analysis software for correction and curve fitting, and for calculating the Ab dissociation rates ( $k_{\text {off }}$ values) or KD values for monoclonal antibodies.

Flow cytometry B-cell profiling and mAb isolation with HCoV S-proteins. Flow cytometry of PBMC samples from convalescent human donors were conducted following methods described previously $32,48,49$. Frozen human PBMCs were resuspended in $10 \mathrm{ml}$ Rosewell Park Memorial Institute 1640 medium (Thermo 
Fisher Scientific, \#11875085) pre-warmed to $37^{\circ} \mathrm{C}$ containing 50\% FBS. After centrifugation at $400 \times g$ for $5 \mathrm{~min}$, the cells were re-suspended in a $5 \mathrm{ml}$ FACS buffer (PBS, 2\% FBS, 2 mM EDTA) and counted. A mixture of fluorescently labeled antibodies to cell surface markers was prepared as 1:100 dilution that included antibodies specific for the T-cell markers CD3 (APC-Cy7, BD Pharmingen \#557757), CD4 (APC-Cy7, Biolegend \#317418), and CD8 (APC-Cy7, BD Pharmingen \#557760); B-cell markers CD19 (PerCP-Cy5.5, Fisher Scientific \#NC9963455), IgG (BV605, BD Pharmingen \#563246) and IgM(PE); CD14 (APCCy7, BD Pharmingen \#561384, clone M5E2). The cells were incubated with the Ab mixture for $15 \mathrm{~min}$ on ice in the dark. The SARS-CoV-2 S protein was conjugated to streptavidin-AF488 (Life Technologies \#S11223), the HCoV-HKU1 S protein to streptavidin-BV421 (BD Pharmingen \#563259) and the HCoV-NL63 S protein to streptavidin-AF647 (Life Technologies \#S21374). Following conjugation, each S protein-probe was added to the $\mathrm{Ab}$-cell mixture and incubated for $30 \mathrm{~min}$ on ice in the dark. FVS510 Live/Dead stain (Thermo Fisher Scientific, \#L34966) in the FACS buffer (1:300) was added to the cells and incubated on ice in the dark for $15 \mathrm{~min}$. The stained cells were washed with FACS buffer and re-suspended in $500 \mu \mathrm{l}$ of FACS buffer/10-20 million cells, passed through a $70-\mu \mathrm{m}$ mesh cap FACS tube (Fisher Scientific, \#08-771-23) and sorted using a Beckman Coulter Astrios sorter, where memory $B$ cells specific to $S$ protein proteins were isolated. In brief, after the gating of lymphocytes (SSC-A vs. FSC-A) and singlets (FSC-H vs. FSC-A), live cells were identified by the negative FVS510 live/dead staining phenotype, then antigenspecific memory $\mathrm{B}$ cells were distinguished with sequential gating and defined as CD3-, CD4-, CD8-, CD14-, CD19+, IgM-, and IgG+. Subsequently, the S protein specific B cells were identified with the phenotype of AF488+BV421 +(SARS-CoV-2/HCoV-HKU1 S protein double positive) or AF488+AF647 +(SARS-CoV-2/HCoV-NL63 S protein double positive). Positive memory B cells were then sorted and collected at single-cell density in 96-well plates. Downstream single-cell IgG RT-PCR reactions were conducted using Superscript IV Reverse Transcriptase (Thermo Fisher, \# 18090050), random hexamers (Gene Link \# 26400003), Ig gene-specific primers, dNTP, Igepal, DTT and RNAseOUT (Thermo Fisher \# 10777019). cDNA products were then used in nested PCR for heavy/light chain variable region amplification with HotStarTaq Plus DNA Polymerase (QIAGEN \# 203643) and specific primer sets described previously ${ }^{50,51}$. The second round PCR exploited primer sets for adding on the overlapping region with the expression vector, followed by cloning of the amplified variable regions into vectors containing constant regions of IgG1, Ig Kappa, or Ig Lambda using Gibson assembly enzyme mix (New England Biolabs \#E2621L) after confirming paired amplified product on 96-well E gel (ThermoFisher \#G720801). Gibson assembly products were finally transformed into competent Esherichia coli cells and single colonies were picked for sequencing and analysis on IMGT V-Quest online tool (http://www.imgt.org) as well as downstream plasmid production for $\mathrm{Ab}$ expression.

Neutralization assay. Under BSL2/3 conditions, MLV-gag/pol and MLV-CMV plasmids were co-transfected into HEK293T cells along with full-length or variously truncated SARS-CoV-1 and SARS-COV2 spike plasmids using Lipofectamine 2000 to produce single-round of infection competent pseudo-viruses. The medium was changed $16 \mathrm{~h}$ post transfection. The supernatant containing MLV pseudotyped viral particles was collected $48 \mathrm{~h}$ post transfection, aliquoted and frozen at $-80^{\circ} \mathrm{C}$ for neutralization assay. Pseudotyped viral neutralization assay was performed as previously described with minor modification (Modified from TZM-bl assay protocol ${ }^{52}$ ). In all, $293 \mathrm{~T}$ cells were plated in advance overnight with Dulbecco's Modified Eagle medium $+10 \%$ FBS $+1 \%$ Pen/Strep $+1 \%$ L-glutamine. Transfection was done with Opti-MEM transfection medium (Gibco, 31985) using Lipofectamine 2000. The medium was changed $12 \mathrm{~h}$ after transfection. Supernatants containing the viruses were harvested $48 \mathrm{~h}$ after transfection. (1) Neutralization assay for plasma. Plasma from COVID donors was heat-inactivated at $56^{\circ} \mathrm{C}$ for $30 \mathrm{~min}$. In sterile 96 -well half-area plates, $25 \mu \mathrm{l}$ of virus was immediately mixed with $25 \mu$ of serially diluted $(3 \times)$ plasma starting at 1:10 dilution and incubated for $1 \mathrm{~h}$ at $37^{\circ} \mathrm{C}$ to allow for $\mathrm{Ab}$ neutralization of the pseudotyped virus. In all, 10,000 HeLa-hACE2 cells/well (in $50 \mu \mathrm{l}$ of media containing $20 \mu \mathrm{g} / \mathrm{ml}$ Dextran) were directly added to the $\mathrm{Ab}$ virus mixture. Plates were incubated at $37^{\circ}$ $\mathrm{C}$ for $42-48 \mathrm{~h}$. Following the infection, HeLa-hACE2 cells were lysed using $1 \times$ luciferase lysis buffer (25 mM Gly-Gly pH 7.8, $15 \mathrm{mM} \mathrm{MgSO} 4,4 \mathrm{mM}$ EGTA, 1\% Triton X-100). Luciferase intensity was then read on a Luminometer with luciferase substrate according to the manufacturer's instructions (Promega, PR-E2620). (2) Neutralization assay for monoclonal antibodies. In 96-well half-area plates, $25 \mu \mathrm{l}$ of virus was added to $25 \mu$ l of fivefold serially diluted $\mathrm{mAb}$ (starting concentration of $50 \mu \mathrm{g} / \mathrm{ml}$ ) and incubated for $1 \mathrm{~h}$ before adding HeLa-ACE2 cell as mentioned above. Percentage of neutralization was calculated using the following equation: $100 \times(1-($ MFI of sample-average MFI of background)/average of MFI of probe alone-average MFI of background)).

ADE assay. Ex vivo ADE quantification was measured using a focus reduction neutralization assay. Monoclonal antibodies were serially diluted in complete RPMI and incubated for $1 \mathrm{~h}$ at $37^{\circ} \mathrm{C}$ with SARS-CoV-2 strain USA-WA1/2020 (BEI Resources NR- 52281) $[\mathrm{MOI}=0.01]$, in a BSL3 facility. Following the initial incubation, the mAb-virus complex was added in triplicate to 384-well plates seeded with 1E4 of K562 or Daudi cells and were incubated at $34^{\circ} \mathrm{C}$ for $24 \mathrm{~h}$. In all,
$20 \mu \mathrm{L}$ of the supernatant was transferred to a 384 -well plate seeded with $2 \mathrm{E} 3 \mathrm{HeLa}$ ACE2 cells and incubated for an additional $24 \mathrm{~h}$ at $34^{\circ} \mathrm{C}$. Plates were fixed with 25 $\mu \mathrm{l}$ of $8 \%$ formaldehyde for $1 \mathrm{~h}$ at $34^{\circ} \mathrm{C}$. Plates were washed three times with $1 \times$ PBS $0.05 \%$ Tween-20 following fixation. $10 \mu \mathrm{L}$ of human polyclonal sera diluted $1: 500$ in Perm/Wash Buffer (BD Biosciences) was added to the plate and incubated at RT for $2 \mathrm{~h}$. The plates were then washed three times with $1 \times$ PBS 0.05\% Tween-20 and stained with peroxidase goat anti-human Fab (Jackson Scientific, 109-035-006) diluted 1:2000 in Perm/wash buffer then incubated at RT for $2 \mathrm{~h}$. The plates were then washed three times with $1 \times$ PBS $0.05 \%$ Tween-20. In all, $10 \mu \mathrm{L}$ of Perm/Wash buffer was added to the plate then incubated for $15 \mathrm{~min}$ at RT. The Perm/Wash buffer was removed and $10 \mu \mathrm{L}$ of TrueBlue peroxidase substrate was added. The plates were incubated for $30 \mathrm{~min}$ at RT then washed once with milli-Q water. The focus forming unit (FFU) per well was then quantified using a compound microscope. The PFU/mL of the monocyte plate supernatant was calculated and graphed using Prism 8 software.

Negative stain electron microscopy. The $\mathrm{HCoV}-\mathrm{HKU} 1 \mathrm{~S}$ protein was incubated with a threefold molar excess of Fab CC40.8 for 30 mins at room temperature and diluted to $0.03 \mathrm{mg} / \mathrm{ml}$ in $1 \times \mathrm{TBS}$ pH 7.4. In all, $3 \mu \mathrm{L}$ of the diluted sample was deposited on a glow discharged copper mesh grid, blotted off, and stained for $55 \mathrm{~s}$ with $2 \%$ uranyl formate. Proper stain thickness and particle density was assessed on a FEI Morgagni $(80 \mathrm{keV})$. The Leginon software ${ }^{53}$ was used to automate data collection on a FEI Tecnai Spirit $(120 \mathrm{keV})$, paired an FEI Eagle $4 \mathrm{k} \times 4 \mathrm{k}$ camera. The following parameters were used: $52,000 \times$ magnification, $-1.5 \mu \mathrm{m}$ defocus, a pixel size of $2.06 \AA$, and a dose of $25 \mathrm{e}^{-} / \AA^{2}$. Micrographs were stored in the Appion database ${ }^{54}$, particles were picked using DogPicker ${ }^{55}$, and a particle stack of 256 pixels was made. RELION $3.0^{56}$ was used to generate the $2 \mathrm{D}$ class averages. The flexibility of the fab relative to the spike precluded $3 \mathrm{D}$ reconstruction.

Statistical analysis. Statistical analysis was performed using Graph Pad Prism 8 for Mac, Graph Pad Software, San Diego, California, USA. Median AUC or reciprocal $50 \%$ binding (ID50) or neutralization (IC50) titers were compared using the non-parametric unpaired Mann-Whitney $U$ test. The correlation between two groups was determined by Spearman rank test. Data were considered statistically significant at ${ }^{*} p<0.05, * * p<0.01, * * * p<0.001$, and ${ }^{* * * *} p<0.0001$.

Reporting summary. Further information on research design is available in the Nature Research Reporting Summary linked to this article.

\section{Data availability}

The authors declare that the data supporting the findings of this study are available within the paper and its supplementary information files or from the corresponding author upon reasonable request. Ab sequences have been deposited in GenBank under accession numbers MW426536-MW426544, MW532169-MW532198. Ab plasmids are available from Dennis Burton under an MTA from The Scripps Research Institute.

Received: 18 September 2020; Accepted: 8 April 2021; Published online: 19 May 2021

\section{References}

1. Angeletti, D. et al. Defining B cell immunodominance to viruses. Nat. Immunol. 18, 456-463 (2017).

2. Arvin, A. M. et al. A perspective on potential antibody-dependent enhancement of SARS-CoV-2. Nature 584, 353-363 (2020).

3. Halstead, S. B. Neutralization and antibody-dependent enhancement of dengue viruses. Adv. Virus Res. 60, 421-467 (2003).

4. Che, X. Y. et al. Antigenic cross-reactivity between severe acute respiratory syndrome-associated coronavirus and human coronaviruses $229 \mathrm{E}$ and OC43. J. Infect. Dis. 191, 2033-2037 (2005).

5. Mateus, J., et al. Selective and cross-reactive SARS-CoV-2 T cell epitopes in unexposed humans. Science 370, 89-94 (2020).

6. Paules, C. I., Marston, H. D. \& Fauci, A. S. Coronavirus infections-more than just the common cold. JAMA 323, 707-708 (2020).

7. Sekine, T., et al. Robust $\mathrm{T}$ cell immunity in convalescent individuals with asymptomatic or mild COVID-19. Cell 183, 158-168.e14 (2020).

8. Huang, A. T. et al. A systematic review of antibody mediated immunity to coronaviruses: kinetics, correlates of protection, and association with severity. Nat. Commun. 11, 4704 (2020).

9. de Assis, R. R., et al. Analysis of SARS-CoV-2 antibodies in COVID-19 convalescent plasma using a coonavirus antigen microarray. bioRxiv https:// www.biorxiv.org/content/10.1101/2020.04.15.043364v1 (2020).

10. Grifoni, A. et al. Targets of T cell responses to SARS-CoV-2 coronavirus in humans with COVID-19 disease and unexposed individuals. Cell 181, 1489-1501 e1415. (2020). 
11. Ng, K. W. et al. Preexisting and de novo humoral immunity to SARS-CoV-2 in humans. Science 370, 1339-1343 (2020).

12. Prevost, J. et al. Cross-Sectional Evaluation of Humoral Responses against SARS-CoV-2 Spike. Cell Rep. Med. 1, 100126 (2020).

13. Cao, L. et al. Differential processing of HIV envelope glycans on the virus and soluble recombinant trimer. Nat. Commun. 9, 3693 (2018).

14. Struwe, W. B. et al. Site-specific glycosylation of virion-derived HIV-1 Env is mimicked by a soluble trimeric immunogen. Cell Rep. 24, 1958-1966 (2018).

15. Kirchdoerfer, R. N. et al. Pre-fusion structure of a human coronavirus spike protein. Nature 531, 118-121 (2016).

16. Pallesen, J. et al. Immunogenicity and structures of a rationally designed prefusion MERS-CoV spike antigen. Proc. Natl. Acad. Sci. USA 114, E7348-E7357 (2017)

17. Wrapp, D. et al. Cryo-EM structure of the 2019-nCoV spike in the prefusion conformation. Science 367, 1260-1263 (2020).

18. Chen, Y., Liu, Q. \& Guo, D. Emerging coronaviruses: genome structure, replication, and pathogenesis. J. Med Virol. 92, 418-423 (2020).

19. Lu, R. et al. Genomic characterisation and epidemiology of 2019 novel coronavirus: implications for virus origins and receptor binding. Lancet 395 , 565-574 (2020).

20. Dennison, S. M. et al. Qualified biolayer interferometry avidity measurements distinguish the heterogeneity of antibody interactions with plasmodium falciparum circumsporozoite protein antigens. J. Immunol. 201, 1315-1326 (2018).

21. Bonsignori, M. et al. Maturation pathway from germline to broad HIV-1 neutralizer of a CD4-mimic antibody. Cell 165, 449-463 (2016).

22. Liao, H. X. et al. Co-evolution of a broadly neutralizing HIV-1 antibody and founder virus. Nature 496, 469-476 (2013).

23. Doria-Rose, N. A. et al. Developmental pathway for potent V1V2-directed HIV-neutralizing antibodies. Nature 509, 55-62 (2014).

24. Landais, E. et al. HIV envelope glycoform heterogeneity and localized diversity govern the initiation and maturation of a V2 apex broadly neutralizing antibody lineage. Immunity 47, 990-1003 e1009. (2017).

25. MacLeod, D. T. et al. Early antibody lineage diversification and independent limb maturation lead to broad hiv-1 neutralization targeting the env highmannose patch. Immunity 44, 1215-1226 (2016).

26. Bhiman, J. N. et al. Viral variants that initiate and drive maturation of V1V2directed HIV-1 broadly neutralizing antibodies. Nat. Med. 21, 1332-1336 (2015).

27. Briney, B. et al. Tailored immunogens direct affinity maturation toward HIV neutralizing antibodies. Cell 166, 1459-1470 e1411. (2016).

28. Escolano, A. et al. Sequential immunization elicits broadly neutralizing antiHIV-1 antibodies in Ig knockin mice. Cell 166, 1445-1458 e1412. (2016)

29. Rogers, T. F., et al. Zika virus activates de novo and cross-reactive memory B cell responses in dengue-experienced donors. Sci. Immunol. 2, eaan6809 (2017).

30. Schultheiss, C. et al. Next-generation sequencing of $\mathrm{T}$ and B cell receptor repertoires from COVID-19 patients showed signatures associated with severity of disease. Immunity 53, 442-455 (2020).

31. Yuan, M. et al. Structural basis of a shared antibody response to SARS-CoV-2. Science 369, 1119-1123 (2020).

32. Rogers, T. F. et al. Isolation of potent SARS-CoV-2 neutralizing antibodies and protection from disease in a small animal model. Science 369, 956-963 (2020).

33. Robbiani, D. F. et al. Convergent antibody responses to SARS-CoV-2 in convalescent individuals. Nature 584, 437-442 (2020).

34. Zost, S. J. et al. Rapid isolation and profiling of a diverse panel of human monoclonal antibodies targeting the SARS-CoV-2 spike protein. Nat. Med. 26, 1422-1427 (2020).

35. Brouwer, P. J. M. et al. Potent neutralizing antibodies from COVID-19 patients define multiple targets of vulnerability. Science 369, 643-650 (2020).

36. Ju, B. et al. Human neutralizing antibodies elicited by SARS-CoV-2 infection. Nature 584, 115-119 (2020).

37. Barnes, C. O. et al. Structures of human antibodies bound to SARS-CoV-2 spike reveal common epitopes and recurrent features of antibodies. Cell 182, 828-842 (2020).

38. West, A. P. Jr., Diskin, R., Nussenzweig, M. C. \& Bjorkman, P. J. Structural basis for germ-line gene usage of a potent class of antibodies targeting the CD4-binding site of HIV-1 gp120. Proc. Natl. Acad. Sci. USA 109, E2083-E2090 (2012).

39. Andrews, S. F. \& McDermott, A. B. Shaping a universally broad antibody response to influenza amidst a variable immunoglobulin landscape. Curr. Opin. Immunol. 53, 96-101 (2018).

40. Pieper, K. et al. Public antibodies to malaria antigens generated by two LAIR1 insertion modalities. Nature 548, 597-601 (2017).

41. Anderson, E. M., et al. Seasonal human coronavirus antibodies are boosted upon SARS-CoV-2 infection but not associated with protection. medRxiv, https://www.medrxiv.org/content/10.1101/2020.11.06.20227215v1 (2020).
42. Poston, D., et al. Absence of SARS-CoV-2 neutralizing activity in prepandemic sera from individuals with recent seasonal coronavirus infection. Clin. Infect. Dis. ciaal 803 (2020).

43. Cohen, S. A., Kellogg, C. \& Equils, O. Neutralizing and cross-reacting antibodies: implications for immunotherapy and SARS-CoV-2 vaccine development. Hum. Vaccin. Immunother. 17, 84-87 (2020).

44. Elshabrawy, H. A., Coughlin, M. M., Baker, S. C. \& Prabhakar, B. S. Human monoclonal antibodies against highly conserved HR1 and HR2 domains of the SARS-CoV spike protein are more broadly neutralizing. PloS ONE 7, e50366 (2012).

45. Poh, C. M. et al. Two linear epitopes on the SARS-CoV-2 spike protein that elicit neutralising antibodies in COVID-19 patients. Nat. Commun. 11, 2806 (2020).

46. Wec, A. Z. et al. Broad neutralization of SARS-related viruses by human monoclonal antibodies. Science 369, 731-736 (2020).

47. Walker, L. M. et al. Broad and potent neutralizing antibodies from an African donor reveal a new HIV-1 vaccine target. Science 326, 285-289 (2009).

48. $\mathrm{Wu}, \mathrm{X}$. et al. Rational design of envelope identifies broadly neutralizing human monoclonal antibodies to HIV-1. Science 329, 856-861 (2010).

49. Sok, D. et al. Recombinant HIV envelope trimer selects for quaternarydependent antibodies targeting the trimer apex. Proc. Natl.Acad. Sci. USA 111, 17624-17629 (2014).

50. Tiller, T. et al. Efficient generation of monoclonal antibodies from single human B cells by single cell RT-PCR and expression vector cloning. $J$. Immunol. Methods 329, 112-124 (2008).

51. Doria-Rose, N. A. et al. New member of the V1V2-directed CAP256-VRC26 lineage that shows increased breadth and exceptional potency. J. Virol. 90 76-91 (2016)

52. Sarzotti-Kelsoe, M. et al. Optimization and validation of the TZM-bl assay for standardized assessments of neutralizing antibodies against HIV-1. J. Immunol. Methods 409, 131-146 (2014).

53. Suloway, C. et al. Automated molecular microscopy: the new Leginon system. J. Struct. Biol. 151, 41-60 (2005).

54. Lander, G. C. et al. Appion: an integrated, database-driven pipeline to facilitate EM image processing. J. Struct. Biol. 166, 95-102 (2009).

55. Voss, N. R., Yoshioka, C. K., Radermacher, M., Potter, C. S. \& Carragher, B. DoG Picker and TiltPicker: software tools to facilitate particle selection in single particle electron microscopy. J. Struct. Biol. 166, 205-213 (2009).

56. Scheres, S. H. RELION: implementation of a Bayesian approach to cryo-EM structure determination. J. Struct. Biol. 180, 519-530 (2012).

\section{Acknowledgements}

We thank all the human cohort participants for donating samples. This work was supported by the NIH CHAVD (UM1 AI44462 to A.B.W. and D.R.B.), and R01 (AI132317, AI073148 to D.N.) awards, the IAVI Neutralizing Antibody Center, the Bill and Melinda Gates Foundation (OPP 1170236 to A.B.W. and D.R.B.). This work was also supported by the John and Mary Tu Foundation and the Pendleton Trust.

\section{Author contributions}

R.A. and D.R.B. conceived and designed the study. T.F.R., N.B., J.R., M.P., L.Y., C.I. and D.M.S. recruited donors, collected and processed plasma and PBMC samples; G.S., W.H., S.C., F.A., D.H., J.R., J.L.T., N.B., L.P., S.V., and J.C. made substantial contributions to the acquisition of data and data analyses; G.S., W.H., S.C., F.A., D.H., J.R., J.L.T., N.B., L.P., S.V., J.C., J.E.V., D.N., A.B.W., T.F.R., D.R.B., and R.A. designed experiments and analyzed the data. R.A. and D.R.B. wrote the paper and all authors reviewed and edited the paper.

\section{Competing interests}

R.A., G.S., W.H., T.F.R., and D.R.B. are listed as inventors on pending patent applications describing the SARS-CoV-2 and HCoV-HKU1 S cross-reactive antibodies. D.R.B. is a consultant for IAVI. All other authors have no competing interests to declare.

\section{Additional information}

Supplementary information The online version contains supplementary material available at https://doi.org/10.1038/s41467-021-23074-3.

Correspondence and requests for materials should be addressed to D.R.B. or R.A.

Peer review information Nature Communications thanks Georgia Tomaras and the other, anonymous, reviewer(s) for their contribution to the peer review of this work.

Reprints and permission information is available at http://www.nature.com/reprints

Publisher's note Springer Nature remains neutral with regard to jurisdictional claims in published maps and institutional affiliations. 
(c) (i) Open Access This article is licensed under a Creative Commons Attribution 4.0 International License, which permits use, sharing, adaptation, distribution and reproduction in any medium or format, as long as you give appropriate credit to the original author(s) and the source, provide a link to the Creative Commons license, and indicate if changes were made. The images or other third party material in this article are included in the article's Creative Commons license, unless indicated otherwise in a credit line to the material. If material is not included in the article's Creative Commons license and your intended use is not permitted by statutory regulation or exceeds the permitted use, you will need to obtain permission directly from the copyright holder. To view a copy of this license, visit http://creativecommons.org/ licenses/by/4.0/.

(C) The Author(s) 2021 